\title{
Anti-BCL2 Antibody
}

National Cancer Institute

\section{Source}

National Cancer Institute. Anti-BCL2 Antibody. NCI Thesaurus. Code C118801.

Any antibody that recognizes apoptosis regulator $\mathrm{Bcl}-2$ protein. 